\title{
VARIACIÓN SINTÁCTICA Y ESTRUCTURACIÓN INFORMATIVA
}

\author{
Catalina Fuentes Rodríguez
}

\begin{abstract}
In this article the author explains that, with the aplication of pragmatic value (the communicative use and the informative content) the concept of linguistic variation needs to be revised.
\end{abstract}

1. La cuestión de la variación lingüística, concretamente la sintáctica, sobre la que pretendemos reflexionar aquí, es un asunto que afecta fundamentalmente a la delimitación de las unidades. Así, cabe preguntarse si cuando detectamos una "variación", más de una forma, estamos ante una invariante o una variante lingüística en el sentido glosemático. Es decir, ante unidades distintas o la misma unidad. En el primer caso a un cambio en el plano formal debe seguir un cambio en el contenido y viceversa. Si esto no ocurre así es porque tenemos más de un contenido para una sola forma o más de una forma para un solo contenido, diferencias que dependen bien de la elección libre e individual del hablante (variantes libres) o vienen impuestas por el contexto (variantes contextuales) ${ }^{1}$.

Eso ha sido perfectamente tratado en el capítulo de la Fonología, pero no queda tan claro en otras parcelas. En este aspecto se han detectado las variantes que dependen de aspectos del entorno social que condicionan el lenguaje (Sociolingüística), o de diferencias diatópicas (Dialectología). Menos se han trabajado en el campo de la Lingüística las variantes puramente individuales, como no sea en la Estilística. Además, generalmente se plantea en el plano léxico o fonético y raramente en la sintaxis.

2. Para la delimitación de variante o invariante es necesario extender el concepto significante a la combinatoria sintagmática, y no sólo a la expresión fonética (Cfr. R.Trujillo:1976 y 1988, y S. Gutiérrez Ordóñez: 1989). Por ejemplo, en orden: "La orden fue obedecida" "El orden fue restablecido", no hay cambio en la expresión fónica del término. Pero sabemos que estas unidades son diferentes, que no tienen ningún rasgo común. Además, en el caso de orden hay un cambio morfológico, de género, expresado por el artículo. Por ello habría que plantear como significante también la combinatoria sintáctica y entonces sí podríamos decir que hay una correlación significante- significado: dos contenidos distintos con

\footnotetext{
${ }^{1}$ Es esta una presentación excesivamente resumida de los planteamientos básicos de esta cuestión. Al ser muy conocida remitimos a cualquier manual de Lingüística de orientación estructural.
} 
dos expresiones diferentes. Es lo que defienden los autores citados para diferenciar homónimos, y verlos como dos signos distintos, como dos invariantes ${ }^{2}$.

Hay otras objeciones: cuando decimos "es un chico guay" frente a "es un chico estupendo". O en: "te presento a un amigo, a un compañero, a un colega...". Usamos una variante de expresión que lleva consigo una variante de contenido: en unos casos diafásica: lenguaje coloquial, juvenil frente a lenguaje formal. ¿Estos son variantes o signos distintos? Hasta ahora se han considerado variantes. O cuando decimos "tenemos un coche nuevo" frente a "tenemos un carro nuevo" estamos ante una diferencia diatópica. También en "Es muy desagradable /Es un malage". Lo mismo ocurre entre bicha/serpiente, jalar/dar(se) prisa $^{3}$, jeringo/ churro. Entre trabajo /currelo: "Hoy tengo trabajo" /"Hoy tengo currelo, curro", hay diferencia de registro, de nivel social. Estas diferencias que estudia la Sociolingüística y la Dialectología (las diafásicas menos usadas) ¿son variantes en sí o signos nuevos, invariantes?

La postura tradicional es que transmiten diferencias de contenido pero "extralingüísticas": relativas a las características externas del hablante: nivel social, lugar geográfico, edad, estrato... Son, pues, un contenido residual no tenido en cuenta sino como un añadido. Sociolingüística y Dialectología serían, pues, disciplinas que se ocupan de la diversidad de manifestación del lenguaje, de las distintas realizaciones de una misma entidad abstracta.

Pero si bien hay que tener en cuenta que hay una base abstracta idéntica (un código), un contenido básico único que permite la inteligibilidad y la koiné, no hay que olvidar que en principio pertenecen a normas distintas y los miembros de una comunidad pueden entender sólo algunas de ellas. No serían propiamente sinónimos porque no pueden intercambiarse en el mismo contexto sin diferencia significativa, ya que cada uno tiene un contexto propio, y al extraerlo de él se produce una extrañeza y se añade un contenido secundario ${ }^{4}$. Cuando en una recepción oficial le presentamos al rector un colega, la comunicación es correcta, puesto que puede interpretarse este término como "persona de la misma profesión", no amigo sin más. Pero no ocurre lo mismo si el término usado es tronco. Puede que el rector no conozca la expresión. Y si la conoce se carga de contenidos subjetivos: de registro coloquial, juvenil, o bien informa del nivel bajo al que pertenece el hablante, que no conoce el término adecuado a la situación comunicativa que tenemos (a no ser que estemos hablándole al rector familiarmente, como a un amigo íntimo).

\footnotetext{
${ }^{2}$ Pero en otras ocasiones podemos pensar que son dos invariantes porque se combinan con elementos distintos y su entorno sintagmático es diferente, pues. La diferencia de contenido debe venir de la unidad en sí, como en orden, y no de los otros elementos del contexto. Así, en alto nos dice Trujillo que su contenido (característica de altura que tiene una persona o que ha adquirido) no son más que matices que se revelan en el uso al ir acompañados de ser o estar y son dichos verbos los que aportan la diferencia significativa: El niño es alto/ está alto. No hay dos unidades, sino la misma, con matices que vienen del contexto.

${ }^{3}$ Jalar, según el DRAE (1992) viene de halar, "tirar de una cuerda". Entre sus valores reconoce el uso figurado en Andalucía y América de "Correr o andar muy de prisa", como intransitivo. Pero también puede encontrarse el uso transitivo. Incluso con el valor de "trabajar".

${ }^{4}$ La Teoría de la Relevancia (Sperber-Wilson) nos dirá que faltará a la máxima de pertinencia (no es adecuado en esa circunstancia comunicativa) y entonces el oyente elaborará un contenido secundario deducido, una implicatura. Cfr. por ejemplo G. Reyes (1995) al respecto o D.Sperber-D.Wilson (1986).
} 
Son consideradas variantes, pues, pero porque se entienden estas informaciones como residuales, como contenidos secundarios, subjetivos, no pertinentes en suma. Sin embargo, son estos los rasgos que oponen y diferencian esas dos unidades.

Nuestra postura es diferente: si hay una diferencia de contenido, aunque sea de contenido de uso, relativo al hablante o al entorno, no hay razón para dejarlo fuera. Esto supondría que sólo se reconoce como contenido distintivo el denotativo, el que viene dado por la referencia de la realidad. Y sólo sería determinante el contexto situacional y no los otros componentes del esquema comunicativo. Así, lo que apunta al hablante no sería información: ni su nivel de uso... No habría diferencia informativa entre decir: "Es un tío guay" frente a "es un señor agradable" en una conferencias. Por ejemplo, imaginemos que en vez de decir que tal lingüista tiene una gran claridad expositiva y su teoría es bastante interesante decimos: "Es un tío guay", con intención de adaptarnos al auditorio: son jóvenes, se intenta romper el hielo, atraer su atención, rebajar la tensión y crear cierta complicidad para que se reciba mejor la conferencia. Aquí no podemos decir que no sea pretendido, elaborado conscientemente, sin una intención de comunicación, como si cada hablante llevara adherida una forma de hablar que viene determinada desde lo extralingüístico y no pudiese manejar todas esas posibilidades en su lenguaje.

Por último, cuando no se conoce más que una norma, no hay posibilidad de elección y por tanto no hay variación en cuanto tal. Además, el hablante siempre informa acerca de su nivel de uso. Admitir la variación tal cual ha sido expuesta parece un contrasentido con la economía del lenguaje. No tiene sentido que existan variantes sin informar de nada más. Por tanto, es necesario matizar el concepto de variante, y hablar, quizás, de rasgos de sistema y rasgos de uso, y no rechazar como distintivos valores que vienen del empleo por un determinado hablante en una situación comunicativa determinada.

3. Hoy día estudiamos el lenguaje oral, coloquial, y en este registro encontramos rasgos que es preciso determinar si pertenecen a nuevas invariantes lingüísticas o, por el contrario, no son más que variantes de otras unidades.

Nadie discute que la lengua, a pesar de su unidad, presenta diferencias en su empleo. Y este aspecto ha sido el único capítulo dedicado al uso real que la Lingüística, digamos estándar, se ha permitido hasta hace unos años. Lo más significativo ha sido el estudio sociolingüístico: descubrir qué factores sociales determinan el uso de variantes distintas. Y así aparecen las diferencias diatópicas, diastráticas y diafásicas. De las primeras se ocupa preferentemente la Dialectología. Sin embargo, ahora la Pragmática viene a decirnos (y las investigaciones sobre la conversación y el lenguaje oral de las que no podemos prescindir) que hay otras diferencias que no son sólo sociales, sino individuales. La Sociolingüística puso el énfasis en lo social del uso. La Pragmática, en lo individual del mismo. Así, una afirmación en el sentido de que el hablante se manifiesta en su discurso, que todo está hecho desde la subjetividad del hablante, implica admitir que hay factores individuales que condicionan el lenguaje. Esto supondría una inmensidad de variaciones que la Lingüística no podría abarcar ni describir, y esa es la postura

\footnotetext{
${ }^{5}$ Sí si es un ejemplo, usado metalingüísticamente.
} 
que adoptó en su primer momento ante este fenómeno. La Pragmática sẻ ocupa de hechos individuales, ergo poco sistematizables, no convencionales, no socializados, una ingente cantidad de datos que además son variaciones, no tendencias. Entramos en lo subjetivo y esto no puede ser descrito. Es extralingüístico, individual.

Pero las investigaciones en este campo han demostrado otra cosa: el componente subjetivo también está convencionalizado, también está formalizado. Y aunque en un texto un elemento apunte a la subjetividad del hablante $\mathrm{X}$, en otro texto a la del hablante $\mathrm{Y}$, lo que transmite sigue siendo lo mismo. Es igual a lo que ocurre con los pronombres. Son contenidos coordenativos ambos, que se aplican en la situación comunicativa concreta. Es decir, en:

"Yo me quedo contigo"

yo tiene una referencia distinta según quién hable y a quién. Pero el valor lingüístico es el mismo: el hablante dice a su oyente que se quedará con él. El contenido de yo es "el que habla", el de tú "el receptor o alocutario". Así también en "¡ojalá vengas esta tarde!" el contenido de alegría me apunta a mí si lo digo yo o a Elena si lo dice ella, pero ojalá indica deseo del hablante en ambos casos. En

"Que... que... que no quiero ir, vamos"

se comienza con un titubeo que indica inseguridad, y vamos expresa el apoyo de la opinión y de lo dicho, sea quien sea el que hable. Indica: "lo que quiero decir es...". Por tanto, hay algo formalizado y no todo lo subjetivo es equivalente a individual y por tanto tampoco a variación. Puede serlo la utilización de ciertas variantes alofónicas: s más sonora, p más explosiva..., de ciertos rasgos fonéticos o incluso morfosintácticos, como por ejemplo la preferencia por elementos continuativos: como yo digo, o sea, ciertamente, verdaderamente... en ciertos hablantes.

Pero según eso todo aspecto subjetivo quedaría en la variación y la subjetividad es una componente fundamental en la lengua. Sin punto de vista del hablante no hay lengua, no hay discurso, y, por tanto, no hay texto.

La relación entre la Pragmática y la Sociolingüística, el ámbito más dedicado a la variación, lo tenemos ya en S.Levinson (1989, 366): "No obstante, la pragmática a su vez puede contribuir en gran medida a la sociolingüística, puesto que al tratar de entender la significancia social de las pautas del uso del lenguaje es esencial entender los procesos y las propiedades estructurales subyacentes que restringen la interacción verbal. Así, por ej., Bernstein (1973: capítulo 6) ha atribuido las pautas de vacilación a causas sociológicas sin entender las motivaciones conversacionales subyacentes a estas pautas (por ej. el papel de la estructura de preferencia)". Lo mismo ha ocurrido con las fórmulas de tratamiento: los sociolingüistas no han entendido la motivación conversacional que tienen ${ }^{6}$.

Así pues, el problema de la variación se debe enfrentar a varias cuestiones:

1) hay variación cuando no hay diferencia en el otro plano: a una diferencia de significante no sigue una diferencia de significado o viceversa. Pero esto parece imposible: implica el duplicar elementos en la lengua y va contra la economía.

\footnotetext{
${ }^{6}$ Este tema de la vacilación se va a ver a continuación más detenidamente.
} 
2) Cuando hay diferencia de forma y una diferencia de contenido pero no de contenido designativo, caben varias posturas: la de la Lingüística tradicional, que admite la variación, y la nuestra, que pone en duda esto. El contenido de nivel de empleo, estrato, registro, características sociales o individuales, también es información transmitida. Además, en estos casos si el hablante desconoce las formas pertenecientes a las otras normas, no hay posibilidad de elección, y por tanto no hay variación. La variación entonces se revela como una cuestión surgida fundamentalmente de una Lingüística del código, no del uso ni de la norma. Así A. Narbona (1995) dice que es innegable la existencia de la variación y que esto no se contrapone con el código: "Nadie ha puesto en duda la existencia de variación lingüística. Asumir que es inherente y consustancial al lenguaje -sólo las lenguas muertas no varían- y que los idiomas han de verse como diasistemas dinámicos no implica echar por tierra la concepción de los mismos como sistemas estructurados. La hipótesis variacionista no se opone dicotómicamente a la idea saussureana de que en la lengua tout se tient.(...) la variación forma parte del sistema" (p. 34). Pero con lo que sí se contrapone es con la consideración de la norma y de los rasgos de uso como distintivos, cosa que intentamos defender. No negamos, pues, que haya contenido codificado que diferencia unidades y contenidos que provienen del uso de una misma unidad abstracta. Pero estos no son menos importantes que aquellos.

3) En el caso de que el hablante domine varias normas, al elegir conscientemente una es porque desea comunicar algo con ello. No es indiferente la elección.

Nosotros no vamos a pararnos en las diatópicas, sino en otras que apuntan propiamente al individuo hablante, las llamadas subjetivas o individuales. En estos casos, si la diferencia entre el elemento A y el elemento B es de subjetividad, de carga modal, esto puede explicarse:

$1^{a}$ postura: como una mera variación de uso, que se contamina en el contexto de las características del hablante, algo que es extralingüístico. En esta postura se rechaza la Pragmática como extralingüística y buena parte del análisis supraoracional, si no todo.

$2^{\mathrm{a}}$ postura: si partimos de que la Pragmática estudia la lengua en el uso, que sólo desde el habla se puede analizar internamente el lenguaje, desde el empleo que se hace en la comunicación concreta, (no hay Lingüística sin tratar el habla), hay que integrar todo lo subjetivo como una componente más. Desde esta perspectiva hay que partir de lo realizado. Todo el lenguaje está para ser manejado por un hablante para decirse a sí mismo, para expresarse. Luego los matices referentes a él son tan importantes como los que describen la realidad. Son dos componentes del esquema comunicativo. Sin olvidar que hablar es un acto egocéntrico.

Por tanto cabría preguntarse si todo lo que hoy son variaciones subjetivas pasarían a ser signos nuevos porque comunican algo, porque la diferencia de contenido transmitida es pertinente, sirve para diferenciarlos y es admitida por la sociedad. Otra cosa es que se considere que esa información subjetiva sea de segundo nivel frente a la referencial. Los rasgos de modalidad, los de nivel de empleo (formal, culto, coloquial...), de énfasis, de registro (periodístico...), toda esta información está codificada, sólo que no descrita totalmente- aún. Únicamente un enfoque pragmático puede dar cuenta de la variación en sí. Si no, tendríamos que decir que es ficticia, o que precisa alguna matización. 
Nuestra postura, pues, es que toda la información relativa a los miembros del esquema comunicativo es importante y sirve para diferenciar las unidades: las relativas al hablante (subjetividad, profesión, intención...), al oyente (lo apelativo, adaptarse al público al que va dirigido); al contexto (ir en línea con lo dicho anteriormente: si me hablan en cheli continuar así...). Y no sólo lo relativo a las diferencias de contenido designativo que surgen de la referencia.

4. Pretendemos reflexionar sobre ciertas "variaciones" que generalmente no se han descrito como unidades distintas, como vehículos de contenidos diferentes, pero que, como vamos a ver, desde el punto de vista supraoracional suponen un cambio en la información transmitida. Si la diferencia informativa existe, también la diferencia de contenido. $Y$ a esa diferencia de contenido sigue una diferencia formal, un apoyo formal. ¿No será, entonces, que estamos ante invariantes? Sólo que esas invariantes son del nivel textual o discursivo, y hemos querido ceñirla a lo morfológico, sintáctico, fonológico y semántico de la palabra, o, todo lo más, de la oración. O a una variante del esquema, cuando hay que localizarla en el uso. Concretamente nos centraremos en cuestiones conocidas de la sintaxis que hemos ido aceptando sin discutir completamente sus implicaciones. Vayamos a los ejemplos para poder llegar a una conclusión.

4.1. ¿Nos hemos preguntado alguna vez si la tendencia a defender que la estructura oracional se compone de Sujeto- Predicado y que lleva a suponer una elipsis en cualquier oración nominal implica considerar estos dos tipos como variantes?:

"Pedro viene conmigo, Lola contigo"

“-¿Dónde está la niña?

-La niña, conmigo"

Estos casos se explican por una elipsis de viene o está, recuperable por el contexto.

¿Es una misma invariante oración con dos manifestaciones distintas dependientes en este caso, suponemos, del contexto? Podríamos decir que si se puede prescindir de un elemento, es para evitar repeticiones y hacer la comunicación más rápida. $\mathrm{O}$ bien que usar esa estructura es una variante individual que aporta algún matiz subjetivo. ¿Sintácticamente son dos posibilidades formales sin trascendencia significativa ninguna? ¿No hay cambio en el otro plano? ¿Son, pues, variantes individuales? En todo caso siempre condicionada contextualmente. Yo no puedo usar una u otra indiferentemente, ya que "Lola contigo" sin un contexto determinado puede significar muchas cosas: "Lola está contigo, vive contigo, habla contigo, está enfadada contigo..."

¿Pero tampoco hay diferencia significativa? Quizás sólo la mayor rapidez informativa en este caso y el valor cohesivo de presuponer una secuencia previa que es la que permite su interpretación, y la catálisis del elemento que falta. Así "Lola contigo" al elidir el verbo precedente se liga más a esa primera parte del enunciado.

No ocurre así en otros casos de oración nominal:

“¡Estupenda respuesta!” / “Es estupenda tu respuesta!”

“¡Magnífica vista!” / “Es magnífica la vista!” 
Hay más carga subjetiva en el primero. Y esto puede llevar incluso a lexicalizaciones:

“¡Menuda sorpresa!”/ “¡Es menuda la sorpresa!” "La sorpresa es menuda”

con cierto cambio significativo del adjetivo: en el primero menudo implica un contenido de engrandecimiento. En el uso con el verbo puede tener este valor o el suyo literal: pequeño.

Más claro en:

"¡Gran carrera!” / "Ha sido una buena carrera"

“¡Estupenda conferencia!" P'La conferencia ha sido estupenda"

“-¿Te parece que vayamos a la playa este fin de semana?

-¡Estupendo!”

Aquí estupendo equivale a "Sí, de acuerdo", con alegría, en este contexto de respuesta emotiva. Hay una diferencia de subjetividad y de modalidad: en la oración nominal emotividad, frente a la mera información en la oración representativa con verbo.

Esta construcción también es habitual en los titulares del texto periodístico, igual que en el publicitario. No informa lo mismo un titular con verbo o sin él:

“Caso Soria, la justicia que no llega” (El País, 23.6.96)

"Liberados en Honduras los 33 nicaragüenses secuestrados" (idem)

En el primero ¿qué reponemos, el verbo ser?:

"El Caso Soria es la justicia que no llega"??

En un subtitular de este: "Cuatro jueces y dos jurisdicciones", ¿es lo mismo que transmite "Hubo cuatro jueces y dos jurisdicciones"? Aquí la información es completa, mientras que si se pone como oración nominal es el titular, el anuncio de algo que debe completarse. Es el tema o tópico del que se va a hablar y que incita al lector a comenzar la lectura. Es la información fundamental, el tópico, y se sitúa fuera del tiempo.

Además, en "Caso Soria, la justicia que no llega" hay una estructura de predicación tras una tematización: hablamos del caso Soria, y establecemos un comentario sobre ello: "es el ejemplo de la justicia que no llega".

Luego no podemos alegremente decir que la oración nominal es una elipsis de la oración completa, una variante contextual, porque lleva otros contenidos añadidos: cohesión con el texto anterior, subjetividad en unos casos y urgencia informativa, pertenecer a un tipo textual: el titular periodístico, anunciar el tema..., o al texto publicitario. Así en este mismo periódico:

"El enemigo americano"

y el subtitular:

"Malestar por el propósito de EEUU de sancionar a Colombia tras la absolución de Samper de recibir dinero de los 'narcos"'.

diferencia, pues, partes en el texto: el titular, como anuncio, del cuerpo de lectura del texto. Marca, pues, un tipo de texto específico: el periodístico, y dentro de él diferencia partes. 
En el texto publicitario es aún más rentable, porque no tiene la misma fuerza informativa y apelativa de mantener la atención del oyente el construir con frases cortas. "Depósito directo. Un interés fijo para su tranquilidad" / "El depósito directo tiene (ofrece) un interés fijo para su tranquilidad". Es mucho más directo el primer ejemplo, atrae más la atención del receptor y por tanto es más persuasivo y más informativo. Según L. Sánchez Corral (1991) al no haber verbo desaparece la coordenada espacio- temporal y emitimos sólo elementos abstractos, nociones, que llegan al receptor como una frase sentenciosa, con valor de generalidad, y nombrando las cosas en su esencia, con lo cual no cabe la posibilidad de opinar, estar o no de acuerdo.

Esto nos lleva también a plantearnos si el tipo textual es un rasgo diferenciador o no. ¿Es variación un texto coloquial con circunloquios, titubeos... frente a una frase culta, estándar, o un anuncio publicitario? Hemos visto que la oración nominal se emplea para decir la información esencial y ser apertura, índice, titular, en el texto periodístico. Pero también el tipo de texto selecciona una construcción sintáctica u otra. Así una misma noticia se ofrecería de tres modos distintos según el tipo de comunicación:

"Verás, me parece, no sé, pero creo que han puesto una bomba en... en Vizcaya, ¿no?"

"Han puesto una bomba en Vizcaya"

"Bomba en Vizcaya"

El primero corresponde a una conversación coloquial, familiar, en que aparecen elementos apelativos al ligarlo al oyente (verás, ¿no?), otros de expresión de la opinión (me parece, no sé) y ciertas repeticiones. En el segundo se da en una oración una información completa, sin matices, es puramente informativo, propio de un lenguaje formal: una exposición. Y en el tercero es propio de un titular periodístico, de nuevo con oración nominal.

¿Esta diferencia de tipo textual genera variantes distintas? No olvidemos que informa de:

- nivel de estilo

- intención comunicativa

- estructura y tipo textual

Son contenidos no sólo subjetivos, individuales del hablante, sino también de este como constructor del texto y del producto ofrecido, de su superestructura. Dudamos mucho de que estas características no sean pertinentes ni diferenciadoras, cuando nos sirven para clasificar los tipos de mensaje que podemos ofrecer. Trasciende a la estructura de los textos.

4.2. Pero hay otros casos donde discutir la variación sintáctica. Así en el campo de los relacionantes. ¿Son variantes los nexos que introducen concesivas?

"No te castigaré aunque me has desobedecido"

Más claro en el otro orden: "Aunque me has desobedecido, no te castigaré". Hay una diferencia de ordenación de la información. No sólo se clarifica la función sintáctica de la oración de aunque, que en la primera formulación puede ser emitida por el hablante como una 
adversativa, como una oposición sin más de dos hechos, en una relación coordinada ${ }^{7}$. En este segundo orden es concesiva y subordina, además.

"Me has desobedecido. No obstante, no te castigaré"

"Me has desobedecido. Sin embargo, no te castigaré"

"Me has desobedecido. En cualquier caso, no te castigaré"

No cabe duda de que todos ellos aportan un contenido relacional del tipo "A pesar de A, no se da la consecuencia esperada sino otra". Pero no podemos sustituir uno por otro sin más. Sus condiciones de uso, sus contextos son diferentes y por tanto su combinatoria, su expresión también. Además cada uno de ellos aporta otros matices que son los que tenemos que decidir si corresponden a varias unidades invariantes o a una sola.

Entre aunque, conjunción y los otros elementos, enlaces conjuntivos ${ }^{8}$, hay una diferente ordenación. Aunque encabeza el obstáculo o la causa inoperante. El orden es: Aunque A, B. O $\mathrm{B}$, aunque A. Se traslada con su cláusula porque es un subordinante. Los otros aparecen entre los dos miembros. A, no obstante B. A: causa. B: efecto.

Cuando usamos no obstante necesitamos establecer una pausa fuerte entre los dos enunciados. Mejor dicho, tenemos que emitirlos como dos enunciados, porque esta parece ser la tendencia, el contexto de uso habitual de no obstante. Igual sin embargo. Luego el que ligue dos actos de decir y no dos palabras, dos contenidos semánticos nada más, o dos sintagmas parece ser su característica principal. ¿Comunica esto algo más? Si no en el plano del contenido designativo, sí añade algo en el plano informativo: Con aunque vemos dos hechos ligados por una estructura causal violada: desobedecer y ser castigado, todo en una sola comunicación, en un solo acto de decir. Sin embargo, en dos enunciados, con no obstante y sin embargo, aparecen como dos informaciones. El hablante se para más en cada una de ellas. El rendimiento informativo es mayor: $\mathrm{A}<$ aunque $>\mathrm{B}$. A y B se afirman en tanto en cuanto ligados por la estructura causal. En A <no obstante $>$ B, la información de A se da en sí misma. Luego se añade una extensión en la que aparece la conexión, y se presenta el.hecho B. Se para más. Hay una diferencia en el nivel informativo. Esto es común para los enlaces conjuntivos ${ }^{9}$. Entre ellos, no obstante y sin embargo, hay una diferencia de empleo: no obstante es marcadamente concesivo. Sin embargo es un archiconector de oposición, que no sólo se usa para lo concesivo, sino también para la adversación. Por tanto, sólo aporta el contenido de oposición sin más. Esto va en línea con lo que K. Baldinger (1970) llamaba "estar virtualmente presente el campo semasiológico". Estar presente, comunicar también sus otros empleos. Es la información total del código la que se activa al hablar, toda ella, no sólo el valor seleccionado de entre todas sus posibilidades, aunque este resalta como principal.

Con en cualquier caso el enunciado no es aceptable completamente. En cualquier caso ${ }^{10}$ exige, como el semantismo de cualquier indica, un conjunto de hechos previos, más de uno,

\footnotetext{
${ }^{7}$ Del mismo modo podría haber aparecido pero con ese valor concesivo: "Me has desobedecido, pero no te castigaré".

${ }^{8}$ Cfr. C.Fuentes (1987).

${ }^{9}$ Que tienen movilidad, aparecen con conjunciones... Cfr. C.Fuentes(1987).

${ }^{10}$ Cfr. C.Fuentes(1996b)
} 
que se presentan como posibilidades a pesar de las cuales se produce B. Son unas circunstancias peculiares de uso más restrictivas que en los demás casos.

"Seguramente me habrás desobedecido y no habrás hecho tus deberes ni arreglado tu habitación. En cualquier caso, no te castigaré".

En cualquier caso hace que lo afirmado en el primer enunciado se plantee como hipotético, que no se tenga en cuenta lo dicho, que se vea no como hechos, sino como posibilidades. Sea como fuere, sea eso así o no, lo importante es B.

4.3. Igual nos ocurre con los causativos. Tenemos diversos nexos para marcar esta relación.

"No me compro este libro porque no tengo tiempo para leerlo"

"No me compro este libro, ya que no tengo tiempo para leerlo".

"No me compro este libro. Es que no tengo tiempo para leerlo".

"No me compro este libro. No tengo tiempo para leerlo"

"No me compro este libro. De hecho, no tengo tiempo para leerlo"(este no es propiamente causativo)

Más lógico: "No tengo tiempo para leer. De hecho, no me compro este libro".

En una primera impresión podríamos ver la equivalencia, si no total casi total, entre porque y ya que (o puesto que, que también podría haber aparecido). Sólo que estas combinatorias tienen un menor nivel de empleo que porque. Son más cultas, parece. Y es una circunstancia de registro, pues, una variante diastrática, en principio. Pero no es sólo eso. Si cambiamos el orden

"Porque no tengo tiempo para leerlo, no me compro este libro"

"Ya que no tengo tiempo para leerlo, no me compro este libro"

esta segunda no es tan aceptable como la primera. ¿Por qué? Con porque se enuncia, se pone el énfasis en la conexión causal de los hechos. Estos no se presentan solos, para ser evaluados en tanto ellos mismos, no tienen fuerza argumentativa en sí, sólo en cuanto los extremos de una relación causal. Luego de lo que se informa es de una relación causal entre ellos, no los dos hechos más la relación causal. Por decirlo de alguna manera, lo que importa de esos hechos son sólo las inferencias, las conclusiones que lo llevan a conectarse entre sí. Un hecho puede ser afirmado y dar lugar a multitud de inferencias, conjeturas..., cosa que el contexto determinará. Aquí sólo interesa lo que lo liga causalmente al otro hecho.

Sin embargo, con ya que parece detenerse más en la afirmación de los dos hechos. Esto puede deberse a que puede usarse como causal de la enunciación, del decir. Aquí no aparece así pero tiene también esos valores. Está menos lexicalizado ya que que porque. Ya que parece más: "Teniendo en cuenta A, se da B". Yo diría que se tematiza ese hecho, se da por conocido. "Una vez (valor que viene del contenido temporal de ya que parece no haberse perdido del todo) que conocemos que se ha producido A, se da B que es su consecuencia". G. Reyes considera que expone algo ya dicho, que se cita (G.Reyes, 1994:600). Según ella en:

"Me voy ya que tienes mucho que hacer"

"tener que hacer se presenta como dicho sugerido por el interlocutor u otra persona, o como algo inferido. Su condición de texto atribuido es evidente en que el interlocutor puede protestar 
diciendo 'Yo no he dicho eso, ¿Quién te ha dicho eso...?. 'Parece estar ligado a lo conocido, a lo dicho o sabido por otros o la comunidad. De ahí que sea más raro encontrarlo en posición inicial, donde parece adoptar el valor de "Dado que... Producido, sabido A..."11

"Ya que lleva un tiempo cerrada la casa, está muy sucia" es un enunciado poco aceptable. Pero "Ya que no tengo tiempo de leerlo, no me he comprado el libro", sí se admite. Puede haber desdoblamiento del hablante en este hecho: "Ya que tú dices que no tengo tiempo de leerlo...". O bien apunta a otro acto de habla: "ya que, como te he dicho, no tengo tiempo de leer...". No se admite ya que si no hay esa posibilidad de adjudicarlo a otro enunciador. Así el hablante lo plantea como citado, no se responsabiliza de ello y por tanto en cierto modo lo pone en duda. Al mismo tiempo, se refiere a una comunicación anterior, a algo ya sabido.

Con es que estamos ante un conector de tipo distinto. Es un enlace, conecta enunciados, no oraciones. Son dos actos de decir. El primero aparece como una afirmación en sí, como un hecho que se afirma con todas sus implicaciones. Luego se restringe en una línea, de todas las que pueden surgir de "no compro el libro"

$$
\begin{aligned}
& \rightarrow \text { "no tengo dinero" } \\
& \rightarrow \text { "no me gusta" } \\
& \rightarrow \text { "el empleado es estúpido y no me atiende bien" } \\
& \rightarrow \text { "está roto o en mal estado"... . }
\end{aligned}
$$

De todas esas posibilidades argumentativas aparece una sola, la que lo liga a la causa que considera más importante el hablante, la causa suficiente para ese efecto, desde el punto de vista del locutor (no tiene por qué ser la única ni estar en el topos, para toda la comunidad, con esa fuerza argumentativa): "no tener tiempo de leerlo".

Eso lo delimita el enunciado que sigue, que lo orienta en la argumentación causativa. Es que presenta ese hecho como tal y como la causa de lo anterior. Es lo que lo justifica. Presenta y llama la atención sobre tal hecho, se focaliza, se le da mucha importancia informativa. Además, se presenta como la causa que justifica lo anterior. No sólo que lo causa, sino que lo justifica, parece haber una simpatía del hablante ante eso... Son dos movimientos enunciativos: primero se enuncia un hecho. Luego se añade la justificación del mismo, por si el oyente no lo ha admitido, no está de acuerdo con el hablante (Cfr. C. Fuentes: 1996c).

En la estructura, sin nexo, se dicen sólo los hechos. La relación causal viene del topos. La tiene que elaborar el oyente. No se dice, se sugiere. El énfasis informativo en los hechos es más fuerte.

De hecho no entra plenamente como un conector causativo. En todo caso introduce una causal de la enunciación:

\footnotetext{
${ }^{11}$ J. L. Girón Alconchel (1991,126): “Notemos dos cosas. Primero, que el contenido de 'condición' se adecua al significado de ya, puesto que éste expresa 'lo esperado del cumplimiento del proceso a la vista de, dado el sentido del mismo'. El significado de ya es, pues, la modalidad (lógica o apreciativa) del enunciado (cf. Maingueneau, 1980:127). Segundo, que la modalidad del enunciado (o de verdad) no es incompatible con la de la enunciación (o de relación), es más, que la primera se sobrepone a la segunda"
} 
"No me compro este libro. De hecho, no tengo tiempo de leerlo"

"Digo esto porque...". Aquí parece que lo que hace es darle también un valor de confirmación o realidad a lo que dice en segundo lugar. "La verdad es..., es una realidad que no tengo tiempo de leerlo". Es un valor cercano a en realidad, que tiene este elemento. Sin embargo, conectando otros dos hechos en el mismo entorno, siguiendo el ejemplo que utilizamos anteriormente:

"La casa estaba muy sucia. De hecho, llevaba un tiempo sin limpiarse"

lo que sigue es lo que hace verificar lo dicho en el enunciado A. Además se plantean los dos hechos en sí, con todo su valor, con toda su carga informativa, de inferencias y de fuerza argumentativa. Son dos enunciados, dos actos de decir. Se añade el valor de indicar algo que prueba lo dicho, que asegura su validez (Cfr. C. Fuentes: 1994). Quizás la ordenación más correcta, ya que de hecho introduce la prueba de A, es la contraria. La prueba es la consecuencia, la verificación del valor de la causa:

"No tengo tiempo de leer. De hecho, no me compro este libro"

Se presupone "aunque me guste, por el hecho anterior, consecuentemente... La causa por la que digo que no tengo tiempo de leer es que no me voy a comprar este libro". Es una causal de la enunciación, y el orden cambia.

"La casa llevaba un tiempo sin limpiarse. De hecho estaba muy sucia"

es más correcto, como vemos. Luego estos conectores supraoracionales no diferencian claramente lo consecutivo de lo causativo, tienen ambas posibilidades de empleo.

Estas unidades, pues, no son conmutables libremente. No es la preferencia individual, el ser más o menos culto, sino que hay otras razones de contenido, de intención comunicativa que condicionan su uso, la elección de la unidad correcta. Luego un análisis supraoracional como el que hemos realizado nos lleva a ver que hay invariantes, que hay contenidos subjetivos, de nivel o rentabilidad informativa..., matices en la conexión, que para nosotros son contenidos nuevos, del mismo nivel y con la misma entidad que otros designativos. Por ello pensamos que sí habría que hablar de unidades distintas, y precisamente por ello la lengua las conserva. Si no, por economía reduciría el paradigma. La cuestión nos lleva siempre al mismo sitio: el problema de la variación radica en que se consideran estos matices contenidos residuales, no pertinentes lingüísticamente. Y nosotros diríamos que sí lo son, puesto que a un cambio de intención comunicativa sigue la elección de un medio distinto.

4.4. En los casos discutidos aparece un fenómeno que hemos ido tratando y que está en la base de toda la diferencia oración/enunciado. Esta distinción es básica hoy en un enfoque que supere el análisis oracional y aborde el texto como unidad máxima del análisis. Ya ha quedado prácticamente aceptada la necesidad de adoptar la distinción entre una unidad de construcción gramatical y otra propia del nivel discursivo, de la realización, del decir. Oración llamamos a la primera, es una entidad teórica, de la gramática, un esquema constructivo todavía no emitido. El enunciado es la mínima unidad del decir, de la realización, de lo dicho, de lo emitido en un espacio-tiempo, a un oyente X en unas circunstancias comunicativas (Cfr. C. Fuentes:1996a). Ese acto de decir, esa unidad supone una intención comunicativa por parte del hablante, el segmentar la información en partes. En el discurso hay un factor importante que es esa 
dosificación de la información, que viene dada desde el hablante, y esta parte, este estrato, como decía G. Rojo (1983), debe ser integrado dentro del análisis del discurso, dentro del análisis lingüístico. Hasta ahora sólo se ha tratado la disposición de la información dentro de la oración: given/new, tema/ rema, pero no dentro del texto. Y esto está muy relacionado con la propia organización del discurso y con la teoría argumentativa, que tanta trascendencia y repercusión está teniendo hoy dentro de las perspectivas lingüístico-pragmáticas en uso. Además, hay factores lingüístico- formales que tienen como misión vehicular diferencias informativas.

Cada enunciado es una unidad informativa y emitir un contenido como un solo enunciado o como dos tiene como consecuencia dar más énfasis informativo a unas partes que a otras:
/1a/ "Fui a ver a María, que estaba enferma"
/1b/'Fui a ver a María. Que estaba enferma"
$12 \mathrm{a} /$ "Me compré ayer un jersey rojo"
$/ 2 \mathrm{~b} /$ "Me compré ayer un jersey. Rojo"
/3a/ "Juan estaba enfermo de rabia"
/3b/ "Juan estaba enfermo. De rabia"

En las frases /b/ se detiene más el hablante en la segunda información: "A propósito, añado algo: "Que estaba enferma", como un dato más, como una justificación del hecho anterior. En la primera es una característica sin más. Luego la intención comunicativa es distinta. Y no sólo la carga informativa, el rendimiento informativo, mayor en el segundo caso y el relieve que en este adquiere la oración de relativo, ya no subordinada en el plano informativo. Esto lo saben muy bien los publicistas. Si comparamos el texto publicitario con el periodístico, por ejemplo, vemos que en el primero hay segmentos cortos, seguidos por pausas mayores, como enunciados propios, para que cada palabra tenga todo su eco informativo y elabore todas sus inferencias. Se juega con todas ellas:

"Tiene regalo. Seguro"- varias lecturas: El regalo es seguro. Estoy seguro que tiene regalo. Te digo que es seguro que tiene regalo.

"Tiene regalo seguro"- una sola lectura: el regalo es seguro.

Ya empezamos a ver cómo en este caso diríamos que hay dos unidades distintas, dos invariantes. Incluso manteniendo la misma estructura sintáctica, originaria o típicamente llamada subordinada:

/4a/ "No suele comer garbanzos porque engordan"

$14 \mathrm{~b} /$ "No suele comer garganzos. Porque engordan"

$15 \mathrm{a} /$ "Me encanta que pongan esta tarde "Daniel el travieso" en la tele porque así mi hijo come bien"

15b/ "Me encanta que pongan esta tarde "Daniel el travieso" en la tele. Porque así mi hijo come bien".

$\mathrm{Al}$ decir los primeros enunciados (a) el hablante liga el hecho a la causa. En el segundo (b) el primer enunciado expresa un hecho y hace al oyente inferir varias cosas: me gusta la 
película... Pero al añadir la causa no sólo añade información, sino que corrige esas inferencias y lleva el proceso argumentativo en otra dirección.

A) quiero decir que la razón de $\mathrm{A}$ es $\mathrm{B}$. Centro infomativo: porque, la conexión.

B) Digo A. Luego digo su causa que es B. Un hecho, al que luego se le quiere añadir algo más. Centro informativo: A, B y la conexión.

Hay dos momentos en la enunciación. Al principio se considera una información completa, y luego en un segundo movimiento enunciativo el hablante recuerda algo, se da cuenta de que no ha quedado completo, añade algo más, una explicación, circunstancia que aclare... Es casi una reformulación.

O en "¿Quieres una torta?", frase ambigua, ya que se infieren varias cosas. Frente a: “¿Quieres una torta? De aceite, jeh!”. Esto último aclara, restringe la ambigüedad, la resuelve en un sentido, pero ya ha sido producida en el primer enunciado. Mientras que: “¿Quieres una torta de aceite?" no crea eso, es una frase inocente. No tiene doble lectura. Y comunica menos.

Es lo mismo que el anuncio: "Santiago. Un millón" Se infiere: ¿un niño tiene tanto dinero?. Luego se aclara: "De pasos por dar".

Luego la diferencia de disposición en un enunciado o dos aporta una información y es una invariante de construcción sintáctica que hay que tener en cuenta. De nuevo añade informaciones:

- da más relieve informativo a los elementos

- puede marcar reformulación

- marca tipos de texto. Es más propia del lenguaje publicitario

- Entre los nexos, los enlaces conjuntivos, a diferencia de las conjunciones, unen enunciados, no oraciones.

Estos son algunos de los valores que conlleva la elección de la disposición en varios enunciados en los casos vistos, aunque con ello no se agotan los matices.

4.5. Entramos en otro campo, el de las partículas, elementos que teóricamente parecen vacíos de contenido, meros elementos marginales, prácticamente casi no se les considera signos, no se les reconoce valor gramatical y menos aún léxico. Quizás el problema es la falta de trabajos sobre estas unidades y una perspectiva o punto de partida inadecuado, a mi parecer, en la investigación sobre ellas.

Veamos el ejemplo siguiente:

“- ¿Qué piensas de los nuevos Planes de Estudio?

-No son mejores que otros

Creo que no son mejores que otros.

Bueno, creo que no son mejores que otros.

Pues, no son mejores que otros.

Bueno, pues, no son mejores que otros. 
Bien, pues, no son mejores que otros.

Yo qué sé, no son mejores que otros.

No sé, no son mejores que otros.

Vamos, no son mejores que otros. No son mejores que otros, vamos.

O sea, no son mejores que otros".

o la acumulación: "Bueno, pues, yo qué sé, no son mejores que otros, vamos".

¿Da igual cualquiera de estas respuestas? ¿Hay diferencia de contenido que siga a esta diferencia de expresión?

Empezar sin introductor frente a la utilización del mismo supone varias diferencias. Si la entonación es aseverativa, neutra, parece una respuesta seca, sin cortesía, con una postura de autoridad del que responde y poco cortés. Se plantea como superior al otro interlocutor y en cierto modo amenaza la imagen de otro. Pero con cierta entonación suspendida ${ }^{12}$ parece exponerlo como una opinión, no una aseveración tajante ${ }^{13}$. Lo mismo ocurre con la aparición de los introductores. Estos llevan consigo los siguientes contenidos:

- ligar con la intervención anterior (aquí una pregunta)

- romper la violencia del inicio y mostrar inseguridad del hablante y cortesía: no ser brusco

- ordenar el pensamiento, sobre todo ante un tema delicado

- No querer expresar propiamente su opinión, su postura. Expresarlo como opinión, sólo se le puede adjudicar al hablante, no se presenta como afirmación general. Es una estrategia de cortesía (cfr. H. Haverkate: 1994, 122-129). Respetan una norma de colaboración en la conversación. Son atenuativos, mitigan la aserción y por tanto no amenazan la imagen del otro. No se pone el hablante por encima del oyente.

Entre ellos hay diferencias, aportan matices distintos:

retardatarios, ordenadores o conectores: bueno, pues

subjetividad: yo qué sé, no sé

énfasis en la enunciación: vamos, o sea-- afán explicativo: reformular, aclarar, recalcar la opinión, la intención comunicativa.

Lo mismo cuando se utilizan como continuativos: primero diferencia el registro: oral/ escrito, coloquial/formal, aparte de que cada hablante tenga una preferencia individual sobre un continuativo o lo use como muletilla (contenido subjetivo e individual).

Pero en el sistema, como invariante lleva consigo esa información sobre el registro, el tipo de texto que tenemos, el tipo de comunicación y entorno en que tienen que darse. $\mathrm{O}$ información subjetiva del hablante como inseguridad, titubeo, no conocer la palabra correcta.

Vamos subraya que es su opinión, lo que quiere decir.

\footnotetext{
${ }^{12}$ Agradezco la aclaración que la profesora R. Vila me hizo a este respecto en la presentación de una primera versión de este texto, en un Seminario de Gramática en Sevilla.

${ }^{13}$ H. Haverkate $(1994,197)$ considera que una curva melódica creciente refleja la intención del hablante de expresarse cortésmente.
} 
yo qué sé marca que es su opinión y centra informativamente la atención ahí.

bueno, pues.. y los otros tienen el valor de mantener cohesionado el discurso, ligado, retomando lo anterior, porque el hablante piensa que ha perdido el hilo el oyente ${ }^{14}$.

Son distintas expresiones, con contenidos distintos en el nivel informativo. Estos ¿son pertinentes? Sí para la Pragmática.

4.6. En el mismo sentido tendríamos que referirnos a otras construcciones que se diferencian por el grado de cortesía que presentan en el acto comunicativo. Así en las exhortaciones:

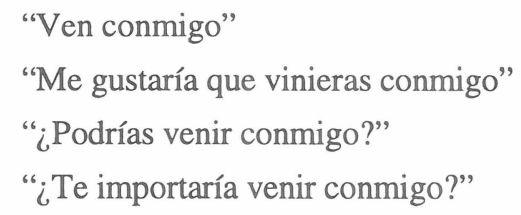

Estos enunciados presentan diferente construcción sintáctica, pero todos tienen el mismo contenido, aunque con diferencia en el grado de cortesía. ¿Es esto un rasgo no pertinente? ¿Es extralingüístico? Depende del uso, sí, pero si genera estructuras significantes distintas son invariantes. Lo que ocurre, de nuevo, es que no se ha superado el análisis de la palabra y de la oración en el código, y no se ha descendido al uso. La Pragmática, al hacerlo, al partir de situaciones de comunicación reales, añade, descubre nuevas invariantes que añadir a las existentes.

Igual, en las respuestas a “Está Juan?”, no es lo mismo decir "Ha salido”, que "Es que ha salido", "Ay, ha salido". La primera es una respuesta poco cortés, sólo aceptable con una postura de privilegio o con una entonación y gestos paralingüísticos de cortesía. Ha salidoooo!. Esta cortesía se consigue sintácticamente exponiéndolo como una justificación: "Es que ha salido", que justificaría "Lo siento, no está aquí, porque ha salido", que se consideraría razón suficiente para ello (no sólo para no estar, sino sobre todo para el acto de habla de expresar su pesar por no agradar al interlocutor). Atenúa el efecto negativo que se supone que produciría la negativa.

Con "Ay, ha salido", el pesar, la actitud modal se expresa con una interjección y es otra estrategia de cortesía.

Luego es que no sólo sirve como un conector de justificación o indicador de una causa, sino que también puede usarse en un contexto conversacional específico para indicar una intervención colaborativa y cortés, para mitigar una negativa, un rechazo.

5. En suma, la variación supone la existencia de más de una manifestación de una sola entidad o invariante. Esas diversas manifestaciones pueden ser por elección individual o exigidas contextualmente.

\footnotetext{
${ }^{14}$ Para el estudio de estas unidades cfr. C.Fuentes- E.Alcaide (1996).
} 
Nosotros, desde una perspectiva supraoracional hemos planteado otras invariantes: por ejemplo, la disposición en diversos enunciados, frente a la disposición en uno solo. Son dos unidades distintas porque el contenido transmitido también lo es. Es de elección libre del hablante, que según lo que quiere transmitir elige una posibilidad u otra. Esto está también en el fondo de la utilización de un enlace conjuntivo frente a una conjunción. Es un elemento sintáctico de pleno derecho. Diferencia incluso tipos de texto.

Además, en nuestro recorrido por diversas unidades aparentemente variantes, que dependen de la subjetividad del hablante, hemos visto que hay circunstancias de uso, valores informativos distintos que las convierten en unidades diferentes: el uso o no de los introductores, los diversos conectores concesivos o los causativos. Desde el punto de vista pragmático parece que la variación en cuanto tal no tiene tanta entidad, debe ser matizada. En la mayoría de las ocasiones se ocultan unidades distintas, aunque los rasgos que las oponen son de subjetividad, registro, tipo textual, intención comunicativa, o jerarquización de la información. Pero estos, para nosotros, son contenidos de pleno derecho, tan importantes como aquellos designativos que suponen una abstracción de la realidad y describen un tipo de objetos. Son las coordenadas del acto comunicativo, sin las que este no existiría.

También D. Sankoff en su artículo "Sociolingüística y variación sintáctica" apunta a que la variación sintáctica se escapa propiamente de este plano y entra en la pragmática. Y considera que "es precisamente en la desdibujada franja que separa el componente sintáctico y el extrasintáctico donde el estudio de la variación sintáctica puede ofrecer sus mayores aportaciones"(D. Sankoff: 1992, 190). Esto implica que para él hay elementos en origen con el "mismo significado" (aunque, no obstante, por ejemplo) que tienen características diferentes, no pertenecientes según él a la sintaxis autónoma. En mi opinión, la sintaxis supraoracional es tan autónoma y pura como la oracional, y lo que hace falta es describir las estructuras discursivas en toda su complejidad. Hay diferencia sintáctica: conjunción /enlace extraoracional, diferencia de forma, y también de matices significativos como hemos mostrado. No es esto una zona límite entre lo sintáctico y lo extrasintáctico, sino una sintaxis discursiva, del texto, desde una perspectiva pragmática, es decir, desde una Lingüística del uso, de la comunicación. La nueva Lingüística, en nuestra opinión. 


\section{BIBLIOGRAFÍA}

K. Baldinger (1970): Teoría Semántica, Madrid, Alcalá

C. Fuentes (1987): Enlaces extraoracionales, Sevilla, Alfar.

C. Fuentes (1994): "Usos discursivos y orientación argumentativa: de hecho, en efecto, efectivamente"- Español Actual, 62, pp. 5-18 (aparecido en enero 1997).

C. Fuentes (1996a): Aproximación a la estructura del texto, Málaga, Ágora.

C. Fuentes (1996b): "El lexema caso y su rendimiento en el ámbito de la conexión", Pragmalingüística, 3-4, pp 329-349.

C. Fuentes (1996c): "Los conectores en la lengua oral: es que como introductor de enunciado", Verba, en prensa.

C. Fuentes \& E. Alcaide (1996): La expresión de la modalidad en el habla de Sevilla, Publicaciones Ayuntamiento Sevilla.

J. L. Girón Alconchel (1991): Tiempo, modalidad y adverbio, Public. Univ. Salamanca.

S. Gutiérrez Ordóñez (1989): Introducción a la Semántica funcional, Madrid, Ed. Síntesis.

H. Haverkate (1994): La cortesía verbal, Madrid,Gredos.

S. Levinson(1989): Pragmática, Barcelona, Teide.

A. Narbona (1995): "Español coloquial y variación lingüística", Actas I Simposio sobre análisis del discurso oral, Univ. Almería, pp. 31-42.

Real Academia Española (1992): Diccionario de la lengua española, Madrid, 21 • ed.

G. Reyes(1994): "La cita en español: gramática y pragmática”- V.Demonte(ed): Gramática del español, El Colegio de México, pp. 591-627.

G. Reyes (1995): El abecé de la pragmática, Madrid, Arco/Libros.

G. Rojo (1983): Aspectos básicos de sintaxis funcional del español, Málaga, Ágora.

L. Sánchez Corral (1991): Retórica y sintaxis de la publicidad, Public. Univ. Córdoba.

D. Sankoff (1992): "Sociolingüística y variación sintáctica", en F. J. Newmeyer (comp): Panorama de la Ling. moderna de la Univ. de Cambridge. IV. El lenguaje. Contexto socio-cultural . Madrid, Visor, pp. 173-196.

D. Sperber- D. Wilson (1986): Relevance. Communication and Cognition. Oxford, Blackwell. (trad. esp.: La Relevancia. Comunicación y procesos cognitivos, Madrid, Visor, 1994).

R. Trujillo (1976): Elementos de Semántica lingüística, Madrid, Cátedra.

R. Trujillo (1988): Introducción a la Semántica española, Madrid, Arco/Libros. 